\title{
Lisinopril Indifferently Improves Heart Rate Variability During Day and Night Periods in Spontaneously Hypertensive Rats
}

\author{
S. ALBARWANI ${ }^{1}$, S. AL-SIYABI ${ }^{1}$, M. O. TANIRA ${ }^{2}$ \\ ${ }^{1}$ Department of Physiology and ${ }^{2}$ Department of Pharmacology and Clinical Pharmacy, College \\ of Medicine and Health Sciences, Sultan Qaboos University, Muscat, Sultanate of Oman
}

Received July 10, 2012

Accepted January 3, 2013

On-line March 14, 2013

\section{Summary}

The aim of this work was to investigate the effect of 10 weeks of lisinopril treatment to spontaneously hypertensive rats (SHRs) on day/night variations of blood pressure, heart rate and autonomic cardio-regulation parameters. Male SHR with surgically implanted radio-telemetry implant that provided direct measurements of arterial pressure and electrocardiogram wave were used. Animals were allocated to two groups ( $n=5$ each). The first group was treated with lisinopril ( $20 \mathrm{mg} / \mathrm{kg}$ by gavage) daily for 10 weeks (treated group); whereas the second was gavaged daily with tap water (untreated group). Arterial blood pressure, ECG and other telemetry parameters were recorded at the start and at the end of 10-week treatment. Collected data were analyzed using specialized software and were statistically tested. In addition to the expected lowering of blood pressure, spectral analysis of R-R intervals revealed that lisinopril treatment for 10 weeks significantly caused 2-3 fold increase in heart rate variability (HRV) during both active and inactive periods. However, R-R interval durations demonstrated variable distribution patterns during those periods. The cause of observed distribution pattern of $R-R$ intervals during active and inactive periods may be of significance to better understand HRV changes and warrants further investigations.
\end{abstract}

\section{Key words}

Heart rate variability - Hypertension - Circadian rhythm • Lisinopril • ACE-inhibitor • Telemetry • SHR

\section{Corresponding author}

S. Albarwani, Department of Physiology, College of Medicine and Health Sciences, Sultan Qaboos University, P.O. Box 35, PC 123 Al-Khod, Muscat, Sultanate of Oman. Fax: +96824143514. E-mail: salbarwani@squ.edu.om

\section{Introduction}

Cardiovascular system homeostasis is a function of complex and intercalated metabolic, neural, humoral and hemodynamic factors that influence blood vessels as well as cardiac muscle performance and structure (Mancia et al. 2007a,b). Disturbance of any of these regulatory factors leads abnormalities in circulatory control, that manifest in various pathological conditions such as essential hypertension (HT) (Singh et al. 2010). Pharmacologic treatment of HT targets the same mechanisms that are involved in cardiovascular homeostasis (Mancia and Grassi 2010).

HT is a global epidemic and a major risk factor to cardiovascular morbidity and mortality (Mancia et al. 2007a,b). Although no definitive cause of HT has been identified (Singh et al. 2010), two systems that are involved in cardiovascular homeostasis have called for more attention than other regulatory systems; viz. the autonomic nervous system (ANS) and the renninangiotensin system (RAS). The two systems 'crosstalk' in HT (Grassi et al. 2001) and their value is thought to extend beyond reducing blood pressure (Del Colle et al. 2007, Grassi et al. 2009, Bakris et al. 2010).

Autonomic modulation of the cardiovascular system reflects on more than one cardiovascular parameter, one of which is heart rate variability (HRV). HRV is a measure that describes temporal variation between consecutive heart beats and it reflects cardiac autonomic regulation. Measurement of HRV has been shown to be a reliable and reproducible non-invasive technique for assessing autonomic function in health and disease (Khand et al. 2006, Rubin et al. 2010). Simple analysis of variation 
in heart rate has been used in clinical practice since the early 1960s and the various methods of analysis used to study the variability of these signals has caught researcher interest in the mid-eighties (Baselli and and Cerutti 1985). At present, HRV has many significant clinical applications (Pumprla et al. 2002) and a prognostic significance (Smilde et al. 2009, Günther et al. 2011).

The autonomic modulation of HRV is associated with day/night cycle variations (Bonnemeier et al. 2003). An example of this circadian variation is the demonstration of the sympathetic dominance on HRV to be in the morning 'active period' compared to the parasympathetic dominance which was shown to be at night 'inactive period' (Ewing et al. 1991).

In this study, we investigated the effect of administering lisinopril (for ten weeks) to spontaneously hypertensive rats (SHRs) on day/night variation of blood pressure, heart rate and autonomic cardio-regulation. The rationale was based on the observation that changes in RAS influence HRV (Task Force of the European Society of Cardiology 1996), the observation that angiotensin converting enzyme inhibitors (ACEIs) have been shown to improve HRV in hypertensive patients (Menezes et al. 2004), the observation that the autonomic modulation of HRV was associated with day/night cycles and the observation that ANS and RAS 'crosstalk' (Grassi 2001). Hence, we hypothesized that lisinopril as an ACEI may have differential day/night effect on HRV in these animals.

\section{Material and Methods}

Animals

Male SHRs rats weighing 180-220 g (ten weeks old) were obtained from Sultan Qaboos University (SQU) Small Animal House facility. The rats were maintained individually in standard cages with wood shavings. All rats had free access to standard laboratory food pellets and water, and were housed in a temperature-controlled room $\left(21-23^{\circ} \mathrm{C}\right)$ with a $12 / 12$-h light/dark cycle with light off at 18:00 h.

All procedures were performed in accordance to SQU Animal Ethics Committee regulations and SQU Guidelines for Care and Use of Laboratory Animals.

\section{Surgical procedure and telemetry implants}

The implantation of radiotelemetry transmitters (C50- PXT Implants; Data Science Int., St. Paul, MN, USA) which provide direct measurements of arterial pressure (AP), electrocardiogram (ECG) wave, temperature and locomotion activity was preformed as previously described (Gordon et al. 2000, Kramer et al. 2000) with minor modification.

Briefly, rats were anesthetized using intraperitoneal (i.p.) injections of $75 \mathrm{mg} / \mathrm{kg}$ ketamine $\mathrm{HCl}$ (Ketasect) and $5 \mathrm{mg} / \mathrm{kg}$ xylazine $\mathrm{HCl}$ (Xylajet). A midline incision $(5-7 \mathrm{~cm})$ was made along the abdominal muscle. The viscera were pushed aside and the descending aorta was located, exposed, and cleaned from the surrounding connective tissue and fat with a wet cotton swab. The telemetry transmitter was inserted into the lumen of the aorta up to $6 \mathrm{~mm}$ above femoral bifurcation and its body was fixed in the abdominal cavity with non-absorbable suture. The abdominal muscle and skin incisions were closed with absorbable suture.

Two ECG leads were routed subcutaneously to the abdominal side of the animal. The negative lead was sutured in the area of the right shoulder and the positive lead in the area of the left groin. The leads were fixed in their position by suturing some muscle around the end of the lead with non absorbable suture.

Prior to the surgery and 5 day thereafter, rats were given enrofloxacin (10 $\mathrm{mg} / \mathrm{kg}$ i.m.). Rats were allowed two weeks to recover from surgery prior to the start of data collection.

\section{Treatment}

SHRs were allocated to two groups, the first $(n=5)$ was treated with lisinopril daily (between 16:00 and $17: 30 \mathrm{~h}$ ) for 10 weeks with $20 \mathrm{mg} / \mathrm{kg} /$ day by gavage, (treated group $(\mathrm{T})$; whereas the second $(\mathrm{n}=5)$ was gavaged daily with tap water (untreated group; (UT). The body weight was monitored daily and the dose was adjusted accordingly.

\section{Data collection}

The transmitted signals were received from the implanted radiotelemetry transmitter via data exchange matrix (placed beneath each animal cage) by a radio receiver (model: RPC-1). Data were collected using computerized data acquisition system software (Dataquest A.R.T. 4.0, Data Sciences, Int) at the start and end of experiment i.e. after ten weeks. The telemetry parameters were monitored for $30 \mathrm{~min}$ at two different periods (being the most convenient to our setting), day time at 7:00 h (inactive period) and night time at 19:00 h (active period), with segment duration of $40 \mathrm{sec}$ every minute. The transitional period from 'active' to 'inactive' 
Table 1. Effect of lisinopril treatment on spontaneously hypertensive rats blood pressure and heart rate.

\begin{tabular}{|c|c|c|c|c|c|c|c|c|}
\hline & \multicolumn{4}{|c|}{ Inactive period } & \multicolumn{4}{|c|}{ Active period } \\
\hline & UT & & $\mathbf{T}$ & & UT & & $\mathbf{T}$ & \\
\hline & Wo & W10 & Wo & W10 & Wo & W10 & Wo & W10 \\
\hline$S B P(m m H g)$ & $170 \pm 7$ & $178 \pm 8$ & $163 \pm 4$ & $97 \pm 5^{*}$ & $166 \pm 8$ & $177 \pm 6$ & $165 \pm 4$ & $84 \pm 6^{*}$ \\
\hline$D B P(m m H g)$ & $110 \pm 6$ & $113 \pm 7$ & $114 \pm 3$ & $59 \pm 7 *$ & $112 \pm 8$ & $118 \pm 7$ & $118 \pm 4$ & $51 \pm 7 *$ \\
\hline$M B P(m m H g)$ & $130 \pm 6$ & $135 \pm 7$ & $130 \pm 3$ & $71 \pm 6^{*}$ & $130 \pm 8$ & $137 \pm 6$ & $134 \pm 4$ & $62 \pm 7 *$ \\
\hline$H R(b p m)$ & $287 \pm 5$ & $260 \pm 3^{*}$ & $309 \pm 15$ & $262 \pm 6^{*}$ & $305 \pm 9$ & $307 \pm 7$ & $308 \pm 11$ & $303 \pm 8$ \\
\hline
\end{tabular}

Systolic blood pressure (SBP), diastolic blood pressure (DBP), mean arterial pressure (MBP) and heart rate (HR) values ( \pm SEM) of spontaneously hypertensive rats treated with lisinopril $20 \mathrm{mg} / \mathrm{kg} /$ day for ten weeks ( $\mathrm{T}$ ) or untreated controls (UT) during inactive (day) and active (night) periods at the beginning (W0) and the end (W10) of the experiment.* indicates statistically significant difference compared to beginning of experiment (W0) of the same group.

period and vice versa was avoided. One day prior the treatment, AP and ECG were recorded from all groups. Data were collected at the end of weeks one, and ten. The ECG and blood pressure waves were sampled at $1 \mathrm{kHz}$ and $500 \mathrm{~Hz}$ respectively.

\section{HRV analysis}

Spectral analysis is a quantitative method used to evaluate the interaction of the sympathovagal tone and modulation of cardiovascular functions (Malliani et al. 1991, Rubini et al. 1993, Montano et al. 1994). Power spectral density of each time series was performed on a frequency domain analysis of HRV by using autoregressive approach. Briefly, a first stationary segment, 150-240 beats length, of beat-to-beat series of ECG was selected to calculate power spectrum based on Levinson-Durbin recursion and the model order (range 814) was automatically selected using Akaike criterion. The autoregressive spectral method permitted to automatically quantify the center frequency and the power of relevant oscillatory component present in the time serious (Malliani et al. 1991, Rubini et al. 1993). Threshold-derivative algorithm was used to analyze RRI utilizing HeartScope software (AMPS. 11C, USA).

The power spectrum of short term HRV contains three power components: a very low (VLF: below $0.20 \mathrm{~Hz}$ ), a low (LF: $0.20-0.75 \mathrm{~Hz}$ ) and a high (HF: 0.75$4 \mathrm{~Hz}$ ) frequency component (Bertagnolli et al. 2008). The power components of LF and HF were expressed in absolute values $\left(\mathrm{ms}^{2}\right)$. The ratio of $\mathrm{LF} / \mathrm{HF}$ was also computed to measure sympathovagal tone. In all analyzed data files there were three exclusion criteria followed. Firstly, the respiratory rate has square coherence value always exceed 0.5 with $\mathrm{HF}$ while with LF is always below 0.5. Secondly, all the series had VLF power less than $80 \%$. Thirdly, the locomotion activity of the rats was not more than 2 count/minute.

\section{Statistical analysis}

All data were expressed as mean \pm SEM. t-test was used to compare the difference. $\mathrm{P}$ value of $<0.05$ was considered significant.

\section{Results}

Systolic blood pressure (SBP), diastolic blood pressure (DBP) and heart rate (HR)

The summary of these data are listed in Table 1. Lisinopril significantly reduced SBP and DBP at 'active' and 'inactive' periods; no changes in blood pressures were observed in untreated SHRs.

The mean values of HR in both groups were not significantly different during active and inactive periods at the start of the experiment. However, after ten weeks, HR was significantly lower compared to their HR values at the start of the experiment only during the inactive period with no changes observed during active period. Treatment did not alter the HR in both periods.

The changes in the RRIs lengths mirrored the changes in HR changes though oppositely being the reciprocal of HR values. We included the RRI (mean values to compare their distribution in accordance to their length in $\mathrm{ms}$ (Fig. 1). Lisinopril treatment for ten weeks showed a trend to re-distribute the number of RRIs. During the inactive period, lisinopril broadened the intervals distribution i.e. RRIs were less frequent in the center of the histogram indicating a shift from a Gaussian to a binomial distribution (Fig. 1B compared to Fig. 1A); whereas it caused a shift-to-left during active period i.e. more RRIs were shorter in duration (Fig. 1D compared to Fig. 1C). 
A

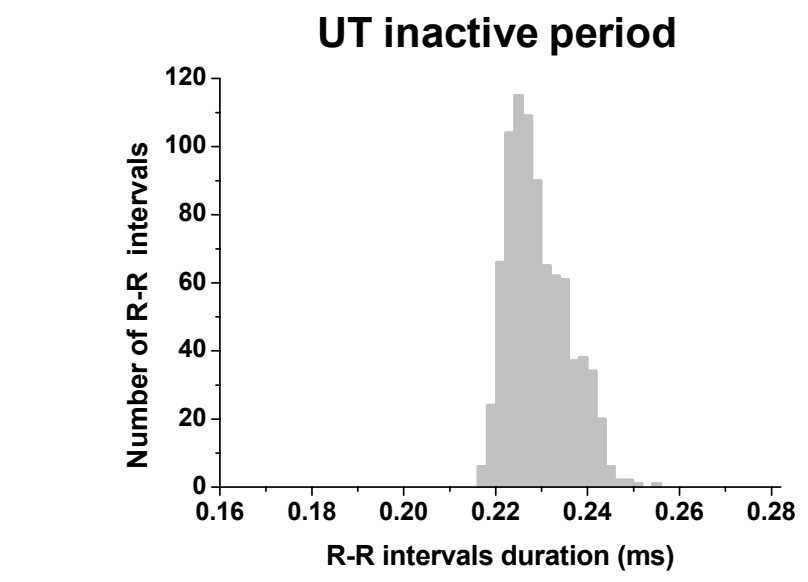

C

B

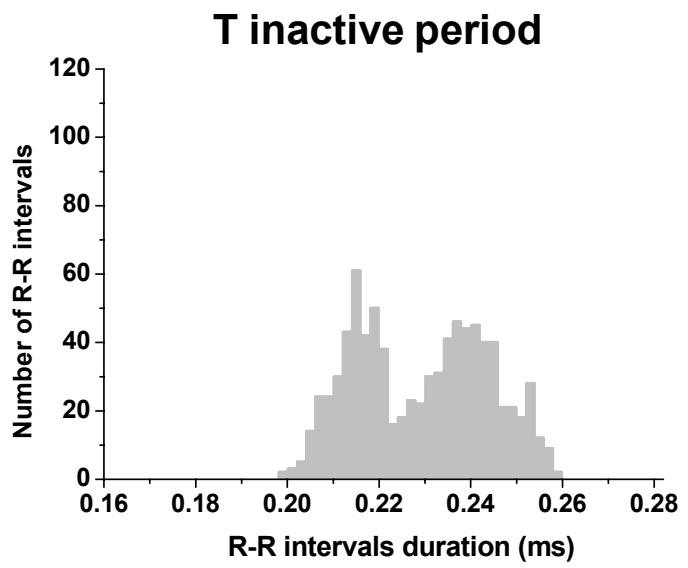

Fig. 1. Distribution of R-R intervals (duration vs. number) as recorded from spontaneously hypertensive rats ten weeks after treatment with lisinopril $20 \mathrm{mg} / \mathrm{kg} /$ day (T) and from untreated controls (UT) during active (night) and inactive (day) periods. Graphs A and C depict data from untreated rats during inactive and active periods respectively, and graphs $\mathbf{B}$ and $\mathbf{D}$ depict data from treated rats during inactive and active periods respectively.

\section{Heart rate variability $(H R V)$}

Compared to week zero, both groups showed increase in HRV at week 10. The difference was significant only during active period. The most pronounced effect of lisinopril treatment was observed on HRV. There was about 2-3 fold increase in HRV due to lisinopril treatment in SHRs (Fig. 2). The effect was even more obvious during 'inactive' period $\left(6.20 \pm 1.03 \mathrm{~ms}^{2}\right.$ and $24.93 \pm 4.2 \mathrm{~ms}^{2}$ ) at the start and after ten weeks respectively, while that of the untreated rats showed slight but insignificant increase from $7.85 \pm 1.4$ to $11.36 \pm 1.87 \mathrm{~ms}^{2}$. At the end of 10 weeks of treatment, the variance of treated was significantly higher than that of UT during both periods $\left(24.93 \pm 1.77 \mathrm{vs}\right.$. $11.36 \pm 1.87 \mathrm{~ms}^{2}$ during inactive and $20.08 \pm 2.82$ vs. $9.8 \pm 1.02 \mathrm{~ms}^{2}$ during
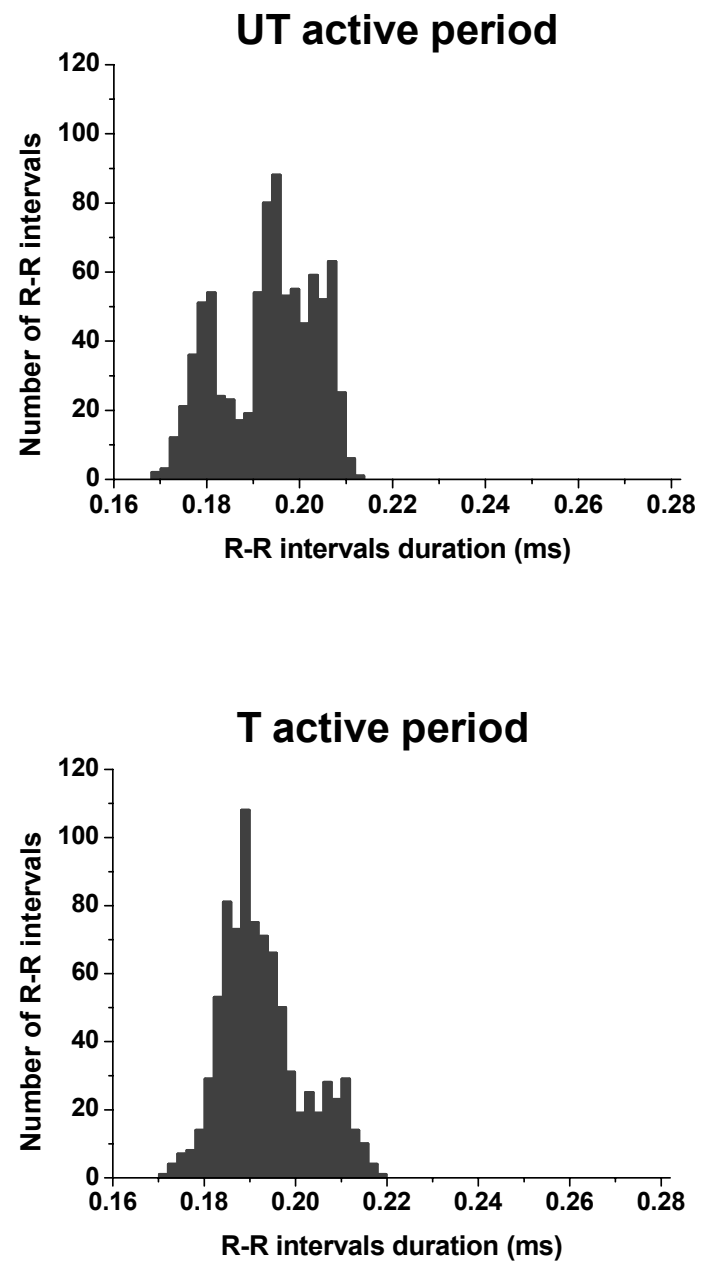

D 

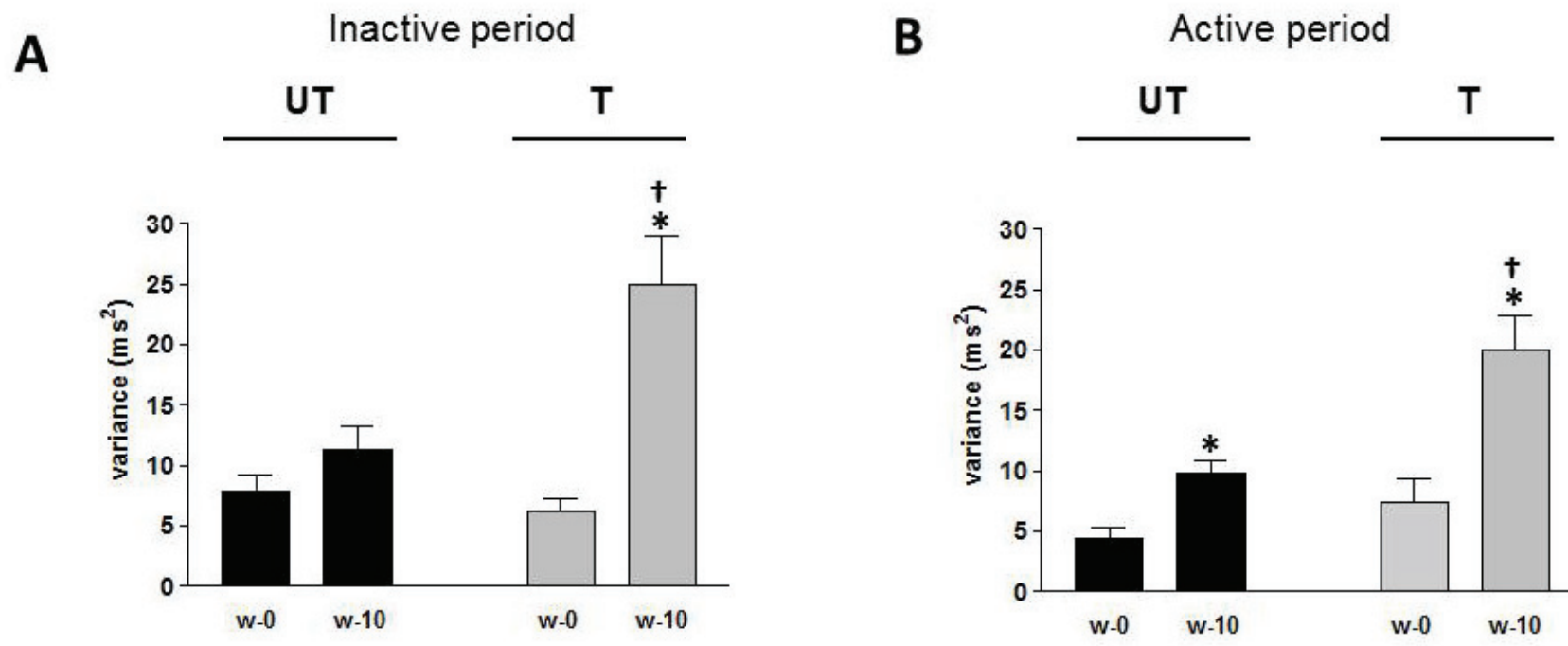

Fig. 2. Mean values $( \pm \mathrm{SEM})$ of heart rate variability (HRV) expressed as variance $\left(\mathrm{ms}^{2}\right)$ during inactive $(\mathbf{A})$ and active (B) periods. In untreated rats (UT), variance showed significant increase in week ten $(w-10)$ compared to start of the experiment $(w-0)$ during active periods only. Lisinopril treatment $(20 \mathrm{mg} / \mathrm{kg} / \mathrm{day})$ for ten weeks significantly increased HRV of treated rats $(T)$ compared to untreated rats (UT). * indicates statistically significant difference compared to $\mathrm{w}-0$ of the same group, ${ }^{+}$indicates statistically significant difference compared to untreated value of the same week.

Table 2. Effect of lisinopril treatment on spontaneously hypertensive rats autonomic nervous system indexes affecting heart rate variability.

\begin{tabular}{|c|c|c|c|c|c|c|c|c|}
\hline & \multicolumn{2}{|c|}{$\begin{array}{l}\text { Inactive period } \\
\text { SHR-UT }\end{array}$} & \multicolumn{2}{|l|}{ SHR-T } & \multicolumn{4}{|c|}{ Active period } \\
\hline & Wo & W10 & Wo & W10 & Wo & W10 & Wo & W10 \\
\hline$H F\left(m s^{2}\right)$ & $4.94 \pm 1.03$ & $7.36 \pm 1.28$ & $3.72 \pm 0.74$ & $15.99 \pm 3.24^{* \dagger}$ & $2.45 \pm 0.31$ & $5.74 \pm 0.45^{*}$ & $3.895 \pm 0.87$ & $14.48 \pm 2.76^{* \dagger}$ \\
\hline$L F\left(m s^{2}\right)$ & $0.39 \pm 0.09$ & $0.82 \pm 0.21$ & $0.31 \pm 0.086$ & $1.16 \pm 0.44^{* \dagger}$ & $0.335 \pm 0.06$ & $0.87 \pm 0.24^{*}$ & $0.425 \pm 0.13$ & $1.59 \pm 0.28^{* \dagger}$ \\
\hline$V L F\left(m s^{2}\right)$ & $2.53 \pm 0.74$ & $3.23 \pm 0.95$ & $2.18 \pm 0.78$ & $6.95 \pm 1.77^{* \dagger}$ & $1.30 \pm 0.40$ & $3.19 \pm 1.10$ & $3.19 \pm 1.23$ & $4.01 \pm 1.35$ \\
\hline$L F / H F$ & $0.079 \pm 0.01$ & $0.111 \pm 0.02$ & $0.085 \pm 0.02$ & $0.134 \pm 0.36$ & $0.150 \pm 0.03$ & $0.153 \pm 0.13$ & $0.105 \pm 0.02$ & $0.124 \pm 0.03$ \\
\hline
\end{tabular}

Values $\left(\mathrm{ms}^{2}\right) \pm$ SEM of heart rate variability components: HF (high frequency), LF (low frequency) VLF; very low frequency and LF/HF ratio recorded from spontaneously hypertensive rats treated with lisinopril $20 \mathrm{mg} / \mathrm{kg} /$ day for ten weeks (T) or untreated controls (UT) during inactive (day) and active (night) periods at the beginning (W0) and the end (W10) of the experiment. * indicates statistically significant difference compared to beginning of experiment (WO) of the same group, ${ }^{+}$indicates statistically significant difference compared to untreated value of the same week.

$\left(4.94 \pm 1.03\right.$ and $\left.2.45 \pm 0.31 \mathrm{~ms}^{2}\right)$ at the start of the experiment, while these values were slightly higher $\left(7.36 \pm 1.28 \mathrm{~ms}^{2}\right.$ and $\left.5.74 \pm 0.45 \mathrm{~ms}^{2}\right)$ ten weeks after, during inactive and active periods; respectively. The LF component values were $0.39 \pm 0.09 \mathrm{~ms}^{2}$ and $0.34 \pm 0.05 \mathrm{~ms}^{2}$ at the start and $0.82 \pm 0.21$ and $0.87 \pm 0.24 \mathrm{~ms}^{2}$ ten weeks after; respectively. The VLF component of these rats followed the same pattern with the values $2.53 \pm 0.74 \mathrm{~ms}^{2}$ and $1.3 \pm 0.4 \mathrm{~ms}^{2}$ at the start of the experiment and $3.32 \pm 0.74$ and $1.30 \pm 0.41 \mathrm{~ms}^{2}$ ten weeks after; respectively (Table 2).

Spectral analysis of data obtained from lisinopril treated SHRs were associated with significant increases (compared to untreated animals) in all components (Table 2). The HF component values were $3.72 \pm 0.74$ and $3.90 \pm 0.87 \mathrm{~ms}^{2}$ at the start and $15.99 \pm 3.24$ and $14.48 \pm 2.76$ $\mathrm{ms}^{2}$ ten weeks after lisinopril treatment during inactive and active periods; respectively. While the LF components values were $0.31 \pm 0.09$ and $0.43 \pm 0.13 \mathrm{~ms}^{2}$ at the start, which increased to $1.63 \pm 0.44$ and $1.59 \pm 0.28 \mathrm{~ms}^{2}$ ten weeks after during inactive and active periods; respectively. The VLF component exhibited the highest increase due to lisinopril treatment. At the start of the experiment it was $2.18 \pm 0.78$ and $3.19 \pm 1.23 \mathrm{~ms}^{2}$ which 
increased to $6.95 \pm 1.77 \mathrm{~ms}^{2}$ and $4.01 \pm 1.35 \mathrm{~ms}^{2}$ during inactive and active periods after ten weeks of treatment. The ratio of LF/HF which is indicative of sympatho-vagal tone showed no significant changes between untreated and treated rats.

\section{Discussion}

This work compared the effects of lisinopril on blood pressure, HRV and indexes of the ANS involvement in cardiovascular control in SHRs during active (night) and inactive (day) times using telemetric monitoring. The drug significantly reduced blood pressure to normotensive range, which is in line with its antihypertensive properties, had no effect on heart rate which was significantly increased in all rats (treated and untreated) during night, an effect that may be explainable by the increased activity of animals during that period. In addition, lisinopril treatment significantly increased the HRV and its three components namely HF, LF and VLF.

Abnormalities in cardiac autonomic regulation have been shown to contribute to mortality regardless of blood pressure level (Hallstrom et al. 2005, Thayer et al. 2010). Therefore, several studies have compared the ability of antihypertensive drugs to better control autonomic cardiovascular parameters independent of hypertension (De Tommasi et al. 2003, Pavithran et al. 2010). The most important of these parameters is HRV using its three components viz. HF, LF and VLF as indexes of autonomic control of heart rate (Stauss and Persson 2006). The HF component is considered to be a product of vagal efferent activity while both vagal and sympathetic modulation are considered to be responsible for LF component. The VLF component is the least defined spectrum of HRV; yet it is speculated to be related to hormonal modulation such as renin-angiotensin system and thermoregulation (Pumrla et al. 2002).

In our study, lisinopril caused 2-3 fold increase in HRV (Fig. 2). Our results are in agreement with that of Banach et al. (2001) and Dias da Silva et al. (2006) who showed that ACE inhibition improves total HRV spectrum and the HF component. Experimental data in humans and animals suggest that the increases in HRV induced by ACE inhibition are mainly due to better modulation of cardiac vagal activity as indicated by increases in HF component (Stauss 2007). However, in our study both HF and LF showed significant increases. Since LF spectral component is indicative of both vagal and sympathetic modulation (Stauss 2007), it is not possible to conclude from our data if sympathetic modulation is also improved. However it may be speculated that the increases in HRV in response to lisinopril treatment are mainly due to increases in vagal modulations since $\mathrm{LF} / \mathrm{HF}$ ratio showed no significant differences. Yet due to the lack of BRS sensivity data, it is not possible to speculate if the observed HRV changes were coupled with changes in BRS or with changes of intracardiac origin (Papaioannou et al. 2012).

Lisinopril significantly increased the VLF component of HRV during active periods only. Circadian rhythm of HR and BP are closely related to circadian fluctuations of ANS function; sympathetic tone being dominant during active periods while vagal tone being dominant during inactive periods (Akita et al. 2002). Accordingly, we analyzed if the effects of lisinopril on HRV and on its components as markers of ANS were different between inactive and active periods. The drug caused indifferent but significant increases in HF and LF components (and hence HRV) during active and inactive periods. Although our data are in line with the observation that autonomic modulation of $\mathrm{HRV}$ is associated with day/night cycle variations (Bonnemeier et al. 2003), they are not in complete agreement with what has been previously reported that sympathetic dominance on HRV to be in the morning 'active period' compared to the parasympathetic dominance which was shown to be at night 'inactive period' (Ewing et al. 1991).

HRV measures beat-to-beat variance of the lengths of RRIs regardless of its nature i.e. it does not specify "how" was that variance achieved? In this study, to answer this question, at least in part, we plotted the numbers of RRIs versus its length in milliseconds (Fig. 2). As the distribution histogram shows, lisinopril effect on HRV was associated with a tendency to increase the number of "longer" RRIs during inactive period (Fig. 1B) but a tendency to increase the number of "shorter" RRIs during active period (Fig. 1D). The shape of the histogram after ten weeks of lisinopril treatment during active period resembles, to a certain degree, the distribution of the untreated rats during the inactive period i.e. binormial distribution and vise versa. Such may add more insight on how the "variability" in RRIs is induced. Our data, in this respect, were not so decisive having not achieved statistical significance. Probably, administering lisinopril for longer than ten weeks or monitoring HRV for longer periods may make such an effect more evident and may statistically manifest. Nevertheless, no direct explanation or implication of the 
effect of lisinopril on distribution of RRIs can be provided. However, a number of speculations may be projected. For example, frequent sudden large beat-tobeat changes in RRIs occur throughout the day and night (Khand et al. 2006) and lisinopril may play a role to modulate these changes.

In conclusion, our study was meant to investigate lisinopril effect in the context of day/night cycle since it has been shown that both autonomic modulation of HRV and ANS/RAS 'crosstalk' were associated with day/night cycles (Grassi 2001). However, such makes control of the cardiovascular system more complex (Hoyer 2007, Golombek and Rosenstein 2010). Theoretically, a differential day/night effect on HRV should, probably, have been noticed.

A limitation of our study is the sampling time of the data which was one hour after changing the light cycle. At that early phase of the light cycle period, the effect of the drug, if any, might not be best demonstrated. An intermediate sampling time during the day/night period, might have shown clearer differential effect of the drug on HRV. On the other hand, the effect of sampling time on the plasma concentration of lisinopril should be negligible since lisinopril concentration, as any other drug, reaches a steady state after 4-5 half-lives, which has been well achieved after the first week of the experiment. Therefore, no influence on HRV should be attributed to lisinopril dosage regimen.

Another limitation of the study is the lack of data from normotensive rats, hence no extrapolation of lisinopril effect could be made to non-hypertensive animals. However, it has been shown that lisinopril antihypertensive properties may be independent of other cardiovascular effects (Porritt et al. 2010).

Our work showed no differential effect on HRV value but showed a tendency to "differentially" affect its distribution. The complexity of the system warrants further work with longer period of observation and measuring animal's activity to ascertain whether or not the rhythmic variation in behavior had influenced HRV.

\section{Conflict of Interest}

There is no conflict of interest.

\section{Acknowledgements}

We would like to thank Prof. Nicola Montano, Department of Clinical Sciences, University of Milan, Internal Medicine II, L. Sacco Hospital, Milan, Italy, for his support in data analysis training.

\section{References}

AKITA M, ISHII K, KUWAHARA M, TSUBONE H: Power spectral analysis of heart rate variability for assessment of diurnal variation of autonomic nervous activity in guinea pigs. Exp Anim 51: 1-7, 2002.

AKSELROD S, GORDON D, UBEL FA, SHANNON DC, BERGER AC, COHEN RJ: Power spectrum analysis of heart rate fluctuation: a quantitative probe of beat-to-beat cardiovascular control. Science 213: 220-222, 1981.

BAKRIS G: Are there effects of renin-angiotensin system antagonists beyond blood pressure control? Am J Cardiol 105: 21A-29A, 2010.

BANACH T, KOLASIŃSKA-KLOCH W, FURGAŁA A, LASKIEWICZ J: The effect of the year angiotensinconverting enzyme inhibitors (ACE I) intake on circadian heart rate variability in patients with primary hypertension. Folia Med Cracov 42: 129-140, 2001.

BASELLI G, CERUTTI S: Identification techniques applied to processing of signals from cardiovascular systems. Med Inform 10: 223-235, 1985.

BERTAGNOLLI M, SCHENKEL PC, CAMPOS C, MOSTARDA CT, CASARINI DE, BELLÓ-KLEIN A, IRIGOYEN MC, RIGATTO K: Exercise training reduces sympathetic modulation on cardiovascular system and cardiac oxidative stress in spontaneously hypertensive rats. Am J Hypertens 21: 1188-1193, 2008.

BONNEMEIER H, WIEGAND UKH, BRANDES A, KLUGE N, KATUS HA, RICHARDT G, POTRATZ J: Circadian profile of cardiac autonomic nervous modulation in healthy subjects: differing effects of aging and gender on heart rate variability. J Cardiovasc Electrophysiol 14: 797-799, 2003.

DE TOMMASI E, IACOVIELlO M, ROMITO R, CECONI C, GUIDA P, MASSARI F, FRANCOLINI G, BERTOCCHI F, FERRARI R, RIZZON P, PITZALIS MV: Comparison of the effect of valsartan and lisinopril on autonomic nervous system activity in chronic heart failure. Am Heart J 146: E17, 2003. 
Del COLle S, MOREllo F, RABBiA F, MilAN A, NASO D, PUGLiSi E, MULATERO P, VEGLIO F: Antihypertensive drugs and the sympathetic nervous system. J Cardiovasc Pharmacol 50: 487-496, 2007.

DIAS DA SILVA VJ, MONTANO N, SALGADO HC, FAZAN JÚNIOR R: Effects of long-term angiotensin converting enzyme inhibition on cardiovascular variability in aging rats. Auton Neurosci 124: 49-55, 2006.

DUPREZ D, DE BUYZERE M, RIETZSCHEL E, RIMBOUT S, KAUFMAN JM, VAN HOECKE MJ, CLEMENT DL: Renin-angiotensin-aldosterone system, RR-interval and blood pressure variability during postural changes after myocardial infarction. Eur Heart J 16: 1050-1056, 1995.

EWING DJ, NEILSON JMM, SHAPIRO CM, STEWART JA, REID W: Twenty four hour heart rate variability: effects of posture, sleep and time of day in healthy controls and comparison with bedside tests of autonomic function in diabetic patients. Br Heart J 65: 239-244, 1991.

GOLOMBEK DA, ROSENSTEIN RE: Physiology of circadian entrainment. Physiol Rev 90: 1063-1102, 2010.

GORDON CJ, PADNOS BK: Prolonged elevation in blood pressure in the unrestrained rat exposed to chlorpyrifos. Toxicology 146: 1-13, 2000.

GRASSI G: Renin-angiotensin-sympathetic crosstalks in hypertension: reappraising the relevance of peripheral interactions. J Hypertens 19: 1713-1716, 2001.

GRASSI G: Assessment of sympathetic cardiovascular drive in human hypertension: achievements and perspectives. Hypertension 54: 690-697, 2009.

GÜNTHER A, SALZMANN I, NOWACK S, SCHWAB M, SURBER R, HOYER H, WITTE OW, HOYER D: Heart rate variability - a potential early marker of sub-acute post-stroke infections. Acta Neurol Scand 126: 189-196, 2012.

HALLSTROM AP, STEIN PK, SCHNEIDER R, HODGES M, SCHMIDT G, ULM K; CAST INVESTIGATORS: Characteristics of heart beat intervals and prediction of death. Int J Cardiol 100: 37-45, 2005.

HOYER D, FRANK B, BARANOWSKI R, ZEBROWSKI JJ, STEIN PK, SCHMIDT H: Autonomic information flow rhythms. From heart beat interval to circadian variation. IEEE Eng Med Biol Mag 26: 19-24, 2007.

KHAND AU, RANKIN AC, CLELAND JGF, GEMMELL I, CLARK E, MACFARLANE PW: The assessment of autonomic function in chronic atrial fibrillation: description of a non-invasive technique based on circadian rhythm of atrioventricular nodal functional refractory periods. Europace 8: 927-934, 2006.

KRAMER K, VOSS HP, GRIMBERGEN JA, MILLS PA, HUETTEMAN D, ZWIERS L, BROCKWAY B: Telemetric monitoring of blood pressure in freely moving mice: a preliminary study. Lab Anim 34: 272-280, 2000.

MALLIANI A, PAGANI M, LOMBARDI F, CERUTTI S: Cardiovascular neural regulation explored in the frequency domain. Circulation 84: 482-492, 1991.

MANCIA G, GRASSI G: Management of essential hypertension. Br Med Bull 94: 189-199, 2010.

MANCIA G, LÜSCHER TF, SHEPHERD JT, NOLL G, GRASSI GM: Cardiovascular regulation: basic considerations. In: Cardiovascular Medicine, $3^{\text {rd }}$ Edition. WILLERSON JT, COHN JN, WELLENS JJ, HOMES DR (eds), Springer-Verlag, London, 2007a.

MANCIA G, DE BACKER G, DOMINICZAK A, CIFKOVA R, FAGARD R, GERMANO G, GRASSI G, HEAGERTY AM, KJELDSEN SE, LAURENT S, NARKIEWICZ K, RUILOPE L, RYNKIEWICZ A, SCHMIEDER RE, BOUDIER HA, ZANCHETTI A ET AL.: 2007 Guidelines for the Management of Arterial Hypertension: The Task Force for the Management of Arterial Hypertension of the European Society of Hypertension (ESH) and of the European Society of Cardiology (ESC). J Hypertens 25: 1105-1187, $2007 \mathrm{~b}$.

MENEZES ADA S Jr, MOREIRA HG, DAHER MT: Analysis of heart rate variability in hypertensive patients before and after treatment with angiotensin II-converting enzyme inhibitors. Arq Bras Cardiol 83: 169-172, 2004.

MONTANO N, RUSCONE TG, PORTA A, LOMBARDI F, PAGANI M, MALLIANI A: Power spectrum analysis of heart rate variability to assess the changes in sympathovagal balance during graded orthostatic tilt. Circulation 90: 1826-1831, 1994.

PAPAIOANNOU VE, VERKERK AO, AMIN AS, DE BAKKER JMT: Intracardiac origin of heart rate variability, pacemaker funny current and their possible association with critical illness. Curr Cardiol Rev 9: 82-96, 2013. 
PAVITHRAN P, PRAKASH ES, DUTTA TK, MADANMOHAN T: Effect of antihypertensive drug therapy on shortterm heart rate variability in newly diagnosed essential hypertension. Clin Exp Pharmacol Physiol 37: e107e113, 2010.

PORRITT MJ, CHEN M, REWELL SS, DEAN RG, BURRELL LM, HOWELLS DW: ACE inhibition reduces infarction in normotensive but not hypertensive rats: correlation with cortical ACE activity. $J$ Cereb Blood Flow Metab 30: 1520-1526, 2010.

PUMPRLA J, HOWORKA K, GROVES D, CHESTER M, NOLAN J: Functional assessment of heart rate variability: physiological basis and practical applications. Int J Cardiol 84: 1-14, 2002.

RUBIN MF, BRUNELLI SM, TOWNSEND RR: Variability - the drama of the circulation. J Clin Hypertens 12: 284$287,2010$.

RUBINI R, PORTA A, BASELLI G, CERUTTI S, PARO M: Power spectrum analysis of cardiovascular variability monitored by telemetry in conscious unrestrained rats. J Auton Nerv Syst 45: 181-190, 1993.

SINGH M, MENSAH GA, BAKRIS G: Pathogenesis and clinical physiology of hypertension. Cardiol Clin 8: 545-559, 2010.

SMILDE TD, VAN VELDHUISEN DJ, VAN DEN BERG MP: Prognostic value of heart rate variability and ventricular arrhythmias during 13-year follow-up in patients with mild to moderate heart failure. Clin Res Cardiol 98: 233239, 2009.

STAUSS HM: Power spectral analysis in mice: What are the appropriate frequency bands? Am J Physiol 292: R902R903, 2007.

STAUSS HM, PERSSON PB: Cardiovascular variability and the autonomic nervous system. J Hypertens 24: $1902-$ $1905,2006$.

TASK FORCE OF THE EUROPEAN SOCIETY OF CARDIOLOGY, THE NORTH AMERICAN SOCIETY OF PACING AND ELECTROPHYSIOLOGY: Heart rate variability: standards of measurement, physiological interpretation and clinical use. Circulation 93: 1043-1065, 1996.

THAYER JF, YAMAMOTO SS, BROSSCHOT JF: The relationship of autonomic imbalance, heart rate variability and cardiovascular disease risk factors. Int J Cardiol 141: 122-131, 2010. 